\title{
PROBLEMS OF FOREIGN STUDENTS' INTEGRATION INTO THE EDUCATIONAL ENVIRONMENT OF A PEDAGOGICAL UNIVERSITY
}

(C) 2019

\author{
Arestova Inessa Yuryevna, candidate of biological sciences, \\ associate professor of Bioecology and Chemistry Department \\ I. Yakovlev Chuvash State Pedagogical University (Cheboksary, Russian Federation)
}

\begin{abstract}
A survey was conducted among foreign students studying at Natural Sciences Education Faculty of the I. Yakovlev Chuvash State Pedagogical University located in Cheboksary, the Republic of Chuvashia, Russia. The methodology was used to diagnose the learning motivation of students and a survey was conducted in order to identify socio-pedagogical conditions of students' adaptation to the university. Leading motives have been established that determine the desire of foreign students to obtain higher education in Russian cities. The dynamics of student motivation changes has been revealed. It is also found that the assessment of the university and faculty management work by foreign students testifies to the favorable social and pedagogical environment that is developed at the faculty and university. Foreign students' poor knowledge of special terminology used for the study of natural sciences is noted. The author identified that it is necessary for foreign students to acquire professional activities of pedagogical education bachelors. Studying at a pedagogical university is demanded by foreign citizens from Central Asia states. Working with foreign students enriches the teaching experience of faculty members. Strengthening multicultural relations, creating conditions conducive to the full self-realization of foreign student's personality facilitates the process of their adaptation and integration into the educational environment. Training a prospective bachelor of pedagogical education as a specialist takes place in the context of motivations change throughout the learning process. At the same time, an important point is the confidence in the future profession. In such conditions, educational and cognitive motives become more important and stimulate students to acquire knowledge in the field of their chosen profession.

Keywords: foreign student; learning and cognitive motivation; adaptation; undergraduate degree; pedagogical university; science education; educational environment; social and pedagogical conditions; questioning; pedagogical experience; Russian higher education; Bologna Process.
\end{abstract}

$* * *$

\section{СОДЕРЖАНИЕ МОДЕЛИ ДУХОВНО-НРАВСТВЕННОГО ВОСПИТАНИЯ МЛАДШИХ ШКОЛЬНИКОВ СРЕДСТВАМИ ПОЗНАВАТЕЛЬНОГО ТУРИЗМА}

\section{(C) 2019}

Бакурова Татьяна Петровна, кандидат педагогических наук, доцент кафедры педагогики и психологии Сибирский государственный университет физической культуры и спорта (г. Омск, Российская Федерация)

\footnotetext{
Аннотациия. В данной статье представлен системный подход к духовно-нравственному воспитанию детей младшего школьного возраста, который предлагается реализовать посредством модели, включающей такие компоненты, как целевой, содержательный, субъектный, результативный. Описываются все компоненты модели. Для её реализации были выбраны формы познавательного туризма с учетом возрастных особенностей детей. Дается описание алгоритма использования различных форм познавательного туризма. Алгоритм применения туристической деятельности в духовно-нравственном воспитании младших школьников разработан на основе принципа концентричности и предполагает участие родителей школьников. Представленная модель духовно-нравственного воспитания строится на краеведческом материале и включает активные и интерактивные формы и методы работы, что позволяет формировать не только знания, но и опыт нравственного поведения. В статье описаны модули освоения окружающего мира последовательно от знакомства с городом, затем с регионом и страной по принципу «расширяющейся и углубляющейся спирали»: от простого созерцания до исследования его и творчества. Приводится описание каждой формы познавательного туризма на материале Омска и Омской области. Предложены варианты привлечения родителей, варианты творческих заданий и итоговых занятий для детей. Модель готова к применению и может служить основой для дальнейших исследований.
}

Ключевые слова: духовно-нравственное воспитание; системный подход; модель духовно-нравственного воспитания; младшие школьники; познавательный туризм; формы социально-культурной деятельности; принцип концентричности; музейный урок; виртуальная экскурсия; интерактивная экскурсия; экспедиция; виртуальное путешествие; прогулка.

Проблема духовности и нравственности занимала умы философов древности Сократа, Платона, Аристотеля. Ею интересовались философы Нового времени Декарт, Лейбниц, Спиноза, английские и французские материалисты XVII-XVIII столетий Локк, Бэкон, Гоббс.
В последние годы в нашей стране этой проблеме стали уделять повышенное внимание на всех уровнях, как в педагогической практике, так и на уровне теоретического осмысления и на государственном уровне. Связано это с теми переменами, которые происходили и происходят в общественном сознании 
и государственной политике. Общество осознает необходимость возрождения традиционной духовнонравственной иерархии ценностей, необходимости коренного пересмотра существующих средств и методов духовно-нравственного воспитания подрастающего поколения России.

Методологическую базу исследования составили различные педагогические концепции. В частности, воспитательные концепции, сформулированные в трудах Я.А. Коменского [1], Л.Н. Толстого [2], стали исходными позициями для определения содержания и средств духовно-нравственного воспитания.

Значительную роль в нашем исследовании сыграли положения по проблеме нравственного воспитания подрастающего поколения, которой посвятили свои труды А. Лихачёв [3], И.А. Соловцова [4], Т.И. Петракова [5] и др.

Гуманистические принципы сотрудничества взрослого и ребенка обоснованы в трудах С.Т. Шацкого [6], В.А. Сухомлинского [7]. Их идеи позволили обосновать содержание и формы работы по духовно-нравственному воспитанию детей младшего школьного возраста. Теория ведущей деятельности, обоснованная в трудах отечественных психологов А.Н. Леонтьева [8], Д.Б. Эльконина [9], Л.С. Выготского [10], легла в основу выбора средств духовно-нравственного воспитания школьников.

Сложность решения задач духовно-нравственного воспитания, помимо всего прочего, обоснована еще и тем фактом, что труднее всего поддаются передаче воспитанникам общечеловеческие ценности, составляющие основу духовно-нравственного воспитания. В связи с этим ученые и педагоги-практики уделяют большое внимание именно разработке форм, методов, приемов, которые позволили бы эффективно выполнять социальный заказ общества - развитие духовно-нравственной личности (Н.Е. Щуркова [11], Т.Е. Васильева [12], О.В. Кожина [13], М.Г. Киселева [14], В.Н. Банников [15] и другие). Важно выбрать такие средства, формы и методы, которые были бы направлены не просто на обогащение знаний о ценностях, но формировали бы ценностное отношение к миру и ценностный опыт.

Среди средств и методов духовно-нравственного воспитания младших школьников значительное место отводится как ведущей - учебной - деятельности, так и другим видам деятельности, отвечающим возрастным особенностям учащихся. Широко используется авторами внеурочная деятельность, общественно-полезная, спортивная. Есть исследования, посвященные выявлению роли туристической деятельности в патриотическом воспитании и других направлений духовно-нравственного воспитания. К ним можно отнести исследования А.А. ОстапцаСвешникова [16], Н.В. Бушмановой [17], Ю.М. Лагусева [18], Т.В. Рябовой [19], С.А. Сергеевой [20] и других. При этом следует отметить, что они касаются работы с детьми разного возраста и молодежи. Исследований, изучающих непосредственно влияние туристической деятельности на развитие детей младшего школьного возраста, недостаточно.

Рассматривая туристическую деятельность, авторы выделяют ряд педагогических условий, которые позволяют осуществлять духовно-нравственное воспитание, используя средства туризма. Прежде всего, к таким условиям относят разнообразие форм социально-культурной деятельности, что позволяет использовать их для достижения самых разных воспитательных целей, в том числе и для духовно-нравственного воспитания подрастающего поколения (М.А. Ариарский). Кроме того, отмечается, что использование любых средств, форм и методов будет эффективным, если они будут соответствовать поставленной цели, если освоение окружающего мира с помощью выбранных форм и методов будет происходить на основе принципа концентричности, постепенного наращивания знаний и умений [21].

К сожалению, все эти условия рассматривались в разных исследованиях отдельно и не были изучены в комплексе.

В связи с этим возникла необходимость разработки системного подхода к духовно-нравственному воспитанию детей младшего школьного возраста, который мы предлагаем реализовать посредством модели, включающей такие компоненты, как целевой, содержательный, субъектный, результативный.

Основной компонент модели духовно-нравственного воспитания - иелевой - предполагает достижения ряда целей, которые были поставлены нами в соответствии с направлениями, обозначенными в Концепции духовно-нравственного развития и воспитания личности гражданина России.

Второй компонент - содержательный - включает в себя формы туристической деятельности, методы и приемы работы с детьми, этапы освоения духовно-нравственных ценностей.

Для реализации модели нами были выбраны известные формы туристической деятельности. Но при этом каждая форма имела определенный алгоритм внедрения. Данный алгоритм предполагал обязательное привлечение родителей на разных этапах деятельности, выполнение творческого задания. Привлечение родителей младших школьников к реализации поставленных задач является важным условием, на наш взгляд, поскольку одним из институтов социализации и, следовательно, духовно-нравственного воспитания является семья.

Содержание работы по духовно-нравственному воспитанию включает три модуля, и в его основу заложено концентрическое построение деятельности. С каждым «оборотом» этой «спирали», охватывающим все более широкую природную и социальную среду, учащиеся уже на более высоком уровне постигают знания, опыт, ценности.

Методы работы с детьми подбирались в соответствии с возрастом и формой организации деятельности. При этом предпочтение отдавалось использованию активных и интерактивных приемов и методов. Вся работа по внедрению модели предполагает прохождение следующих этапов.

Первый, познавательно-мотивационный, этап работы предполагает приобретение младшими школьниками первичных социальных знаний об устройстве общества, социально одобряемых и не одобряемых формах поведения в обществе и т.п. Воспитание приближено к обучению, при этом предметом воспи- 
тания являются знания о ценностях, духовности, нравственности.

На эмоционально-оценочном этапе основное внимание педагога было уделено созданию возможности для реализации имеющихся у детей знаний в оценочные суждения. Здесь осуществляется получение обучающимися опыта переживания позитивного отношения к базовым ценностям общества, ценностного отношения к социальной действительности в целом. Воспитание реализуется в контексте жизнедеятельности школьников, и ценности могут усваиваться ими в форме отдельных нравственно ориентированных поступков. На данном этапе особое значение имеет взаимодействие обучающихся на уровне клас$\mathrm{ca}$, образовательного учреждения, т.е. в защищённой дружественной среде, в которой ребёнок получает первое практическое подтверждение приобретённых социальных знаний, начинает их ценить. Это позволяет младшему школьнику сформировать свое отношение, свою оценку той или иной жизненной ценности.

На третьем этапе - деятельностном - необходимо разработать и реализовать ряд мероприятий, направленных на решение основных проблем духовнонравственного воспитания младших школьников. На этом этапе создаются необходимые условия для участия обучающихся в социально значимой деятельности и приобретения ими элементов опыта нравственного поведения и жизни на основе взаимодействия педагогов и воспитанников.

Третий компонент модели - субъектный - направлен на обозначение основных групп взаимодействия. В нашей модели субъектами являются дети младшего школьного возраста, их родители, учителя, библиотекари, музейные работники.

Особенность нашей модели в том, что дети, на которых направлена её реализация, являются не объектами, а активными вовлеченными участниками процесса духовно-нравственного воспитания. Развитие личности обучающегося, формирование его социальной компетентности становится возможным благодаря воспитательной деятельности всех субъектов духовно-нравственного развития и воспитания, а также собственным усилиям самого обучающегося.

Заключительный компонент модели - результативный, который включает в себя планируемые результаты внедрения модели духовно-нравственного воспитания и достигнутые результаты.

К планируемым результатам мы относим появление таких эффектов духовно-нравственного развития и воспитания обучающихся, как освоение российской идентичности, базовых национальных ценностей, развитие нравственного самосознания, формирование позитивного отношения к жизни, доверия к людям и обществу.

Для выявления достигнутого результата после каждого модуля проводится диагностика по выявлению динамики результатов духовно-нравственной воспитанности младших школьников. Затем, исходя из полученных результатов, корректируется работа по следующему модулю. После внедрение и апробации всей модели проводится заключительная диагностика, которая позволяет определить, достигли ли дети планируемых результатов духовно-нравственного воспитания.
Первый модуль называется «Это мой город». Ребенок начинает знакомство сначала со своего города, района, узнает новые интересные достопримечательные места, знакомится с ближайшим окружающим миром. Затем следует второй модуль «Мой любимый край», который предполагает уже изучение ближайших окрестностей своего города - области. Третий модуль - «Страна, где я живу» охватывает ознакомление и изучение главных городов России. Освоение окружающего мира происходит от простого созерцания - ознакомления с ним - до изучения, исследования его, проявления творчества, то есть в диалектическом движении от простого к сложному при прохождении каждого модуля.

Целью первого модуля «Это мой город» является воспитание ценностного отношения к малой родине.

В этом модуле можно выделить 5 блоков: интерактивная экскурсия в Омскую крепость «С чего начинается Родина...»; музейный урок «Известные люди моего города»; экскурсия по храмам, соборам города; путешествие в парк Победы; обзорная экскурсия по городу.

Интерактивная экскурсия предполагает театрализованное, костюмированное посещение Омской крепости с мастер-классом от местных мастеров, которое позволит вовлечь младших школьников и их родителей в активное взаимодействие с экскурсоводом, рассказчиком. Итоговое задание этого блока - проведение в школе викторины и выставки-конкурса рисунков по мотивам экскурсии.

Музейный урок можно провести в Литературном музее им. Ф.М. Достоевского. Помимо урока в самом музее можно посетить памятники знаменитым людям, жившим в городе Омске и прославившим его. После того, как детям станет известна связь этих людей с родным городом, необходимо привлечь их внимание к проблеме охраны памятников, правильного отношения к таким объектам - предметам материальной культуры страны и малой Родины. Организовать трудовой десант и привести в порядок территорию вокруг памятников и сами памятники. Итоговое задание в этом блоке - оформить стенд для школы «Они жили в нашем городе».

Такие мероприятия формируют мировоззрение учащихся, нравственную и этическую культуру, развивают наблюдательность, влияют на формирование взглядов, вкусов, помогают выбрать линию поведения. Активное включение родителей в педагогически организованный воспитательный процесс обеспечивает нравственное развитие не только ребенка, но и семьи.

Прогулка в парк Победы проводится как однодневное туристическое путешествие. Отличие этой формы от предыдущих в том, что здесь у каждого ребенка будет своя функциональная обязанность по совершению путешествия (ответственные за цветы, видеофотосъемку, составление маршрута и пр.).

Перед путешествием необходимо рассказать детям о Великой Отечественной войне, просмотреть фильмы на эту тему, проинструктировать о поведении в Парке Победы, а также распределить между школьниками их роли на это путешествие.

Итоговым творческим заданием будет создание школьниками семейной летописи. 
Завершающей формой в этом модуле является обзорная экскурсия по городу с участием родителей. Это итоговое занятие, которое обобщает все мероприятия первого модуля. Маршрут обзорной экскурсии охватывает все основные и наиболее важные исторические достопримечательности города. Итоговое задание по модулю школьникам совместно с родителями - создать путеводитель по родному городу.

Следующий модуль называется «Мой любимый край».

Цель: Формировать представление о родном крае как части большой страны.

В этом модуле также можно выделить 5 блоков: прогулка на теплоходе в Ачаирский монастырь; экспедиция в Большереченский зоопарк; путешествие по карте Омской области; виртуальное путешествие «В гости к народам Омской области»; экскурсия в краеведческий музей.

Прогулка на теплоходе в Ачаирский монастырь совершается с целью отдыха и ознакомления с природой родного края, с историей возникновения монастыря и архитектурой его соборов и часовен и другими достопримечательностями по пути следования (а также может включать участие в церковной службе и купание в святом источнике). Пока дети плывут на теплоходе, следует обращать их внимание на красоту природы родного края, вызывая потребность бережно относиться к ней.

Итоговым заданием в этом блоке является создание текстов (объявления, рекламы, плакаты, инструкции и пр.) на тему бережного отношения и охраны природы.

Экспедиция в Большереченский зоопарк проводится с участием родителей. Каждый ребенок получает научное задание «Юный зоолог» - выбирают себе в зоопарке питомца, наблюдают и ухаживают за ним. Также можно провести мини-конференцию на тему Красной книги «Их осталось мало». Ребята могут подготовить доклад о том или ином исчезающем виде. Предполагается проведение после экспедиции в зоопарк «Зоовикторины».

Итоговыми будут вариативные задания на выбор самих школьников: фотоконкурс «Мой зоопарк» по мотивам экспедиции; литературный конкурс «Наш дом - планета Земля» (рассказы, сказки, пьесы); конкурс плаката «SOS».

Далее при реализации задач модуля проводится путешествие по карте Омской области. Дети, «передвигаясь» по карте Омской области, «читают» ее: рассказывают о растительности, животном мире, людях, промыслах и т.п. Это обобщающее занятие, которое требует определенной подготовки от каждого ученика. Домашние задания с выполнением самостоятельной работы могут предусматривать участие родителей.

Следующий блок - виртуальное путешествие «В гости к народам Омской области». Преимуществами являются доступность, возможность повторного просмотра, наглядность, наличие интерактивных заданий и многое другое. Виртуальное путешествие является наиболее эффективным средством для демонстрации особенностей национального состава населения города Омска. Оно позволит наглядно продемонстрировать многообразие народов, проживающих в городе.
В этом путешествии младшие школьники узнают историю появления в Сибири различных национальных групп, познакомятся с языком, традиционными ремеслами и жилищем, национальной одеждой, обрядовыми праздниками и фольклором разных народов. А творческие задания позволят дополнить сведения о представителях разных национальностей, проживающих в Омском Прииртышье, их нравах и обычаях.

Итоговое творческое задание - составить кроссворд по теме: «Население Омской области».

Заключительный блок - экскурсия в краеведческий музей. Основные экспозиции музея раскрывают перед посетителями историю края, его природные условия, традиционную культуру как современного населения Омского Прииртышья, так и духовный быт наших предков.

Завершает работу по этому блоку и модулю интеллектуальная игра «Люби и знай свой край».

Третий модуль «Страна, где я живу».

Цель этого модуля - формировать обобщенное представление о своей Родине, чувство гордости и уважения.

Этот модуль включает в себя два больших блока: заочное путешествие по «Золотому кольцу» России; цикл виртуальных экскурсий «Две столицы».

Первый блок - заочное путешествие по «Золотому кольцу» России. Предполагает использование интерактивной доски и карты России. Школьники «передвигаются» по карте - рассказывают о каждом городе, просматривают видеоэкскурсии. Ученики выполняют домашние задания вместе с родителями, работают с энциклопедиями. Занимаются самостоятельным изучением достопримечательностей и объектов путешествия, чтобы потом подготовить интересный рассказ, показ, экскурсию и пр. для заочного путешествия в классе. Каждый ребенок чувствует свою ответственность перед коллективом, т.к. понимает, что без его информации путешествие будет неполным, незаконченным.

Последний блок в модуле - виртуальная экскурсия «Две столицы». Эта форма включает в себя цикл виртуальных экскурсий, которая также предполагает со стороны ребят самостоятельную работу с книгами и энциклопедиями и подготовку экскурсии по выбранному объекту.

Таким образом, каждый модуль имеет завершенный цикл и может существовать как самостоятельный, но в то же время связан с другими модулями. В каждом модуле используются формы социальнокультурной деятельности, соответствующие целям формирования духовно-нравственных ценностей. По итогам освоения каждого модуля предусмотрена диагностика результативности. Полагаем, что такой алгоритм использования средств туризма в работе с детьми младшего школьного возраста будет способствовать эффективному освоению базовых ценностей, а значит, духовно-нравственному воспитанию детей.

Разработанная нами модель была внедрена в учебный процесс младших школьников. Внедрение данной модели при соблюдении ряда условий позволило эффективно повлиять на процесс духовно-нравственного воспитания школьников. 
К таким условиям относятся реализация принципа системности и поэтапности в освоении младшими школьниками духовно-нравственных понятий и ценностей; соответствие форм социально-культурной деятельности целям формирования духовно-нравственных ценностей; освоение окружающего мира по принципу «расширяющейся и углубляющейся спирали»: от простого созерцания - ознакомления с ним - до изучения, исследования его и творчества.

Таким образом, можно констатировать, что разработанная нами модель духовно-нравственного воспитания детей младшего школьного возраста средствами познавательного туризма, включающая содержательный, целевой, субъектный и результативный компоненты, эффективно решает задачи духовно-нравственного воспитания подрастающего поколения.

\section{Список литературы:}

1. Коменский Я.А. Педагогическое наследие / сост. В.М. Кларин, А.Н. Джуринский. М.: Педагогика, 1989. $416 \mathrm{c}$.

2. Толстой Л.Н. Педагогические сочинения / сост. Н.В. Вейкшан. М.: Педагогика, 1989. 544 с.

3. Лихачёв А. Духовно-нравственная жизнь в категориях психологии // Московский психотерапевтический журнал. 2005. № 3. С. 20-50.

4. Соловцова И.А. Законы духовной жизни человека как основа духовного воспитания // Проблемы духовного воспитания: Гуманитарно-целостный подход: мат-лы «круглого стола», 20 октября 2005 г. / сост. И.А. Соловцова; под ред. Н.М. Борытко. Волгоград: ТЦ «ОПТИМ», 2006. С. 5-10.

5. Петракова Т.И., Евладова Е.Б., Макеева С.Г. Духовно-нравственное воспитание в начальной школе: науч.-метод. рекомендации. М.: ИМПЭТО, 2004. $96 \mathrm{c}$.

6. Шацкий С.Т. Педагогические сочинения. В 4 т. Т. 1. М.: Изд-во Акад. пед. наук РСФСР, 1962. 503 с.

7. Сухомлинский В.А. Как воспитывать настоящего человека. М.: Педагогика, 1989. 288 с.

8. Леонтьев А.Н. Деятельность. Сознание. Личность. М.: Академия, 2004. 352 с.
9. Эльконин Д.П. Психология обучения младшего школьника. М.: Знание, 1974. 209 с.

10. Выготский Л.С. Психология. М.: ЭКСМОПресс, 2000. 1008 c.

11. Щуркова Н.Е. Система воспитания в школе и практическая работа педагога. М.: АРКТИ, 2007. $152 \mathrm{c}$.

12. Васильева Т.Е. Музейная педагогика как средство формирования духовно-нравственных ценностей // Воспитание школьников. 2011. № 4. С. 37-41.

13. Кожина О.В. «Когда прочитаны былины...»: Урок литературного чтения в 4-м классе // Практика школьного воспитания. 2012. № 4. С. 12-17.

14. Киселева М.Г. Интернет-проект как средство духовно-нравственного развития обучающихся // Практика школьного воспитания. 2012. № 4. С. 25-31.

15. Банников В.Н. Духовно-нравственное воспитание и развитие обучающихся во внеурочной деятельности // Начальная школа. 2012. № 8. С. 41-45.

16. Остапец-Свешников А.А. Туристическая деятельность как средство преодоления педагогической запущенности подростков: автореф. дис. ... канд. пед. наук. М., 1974. 185 с.

17. Бушманова Н.В. Туристическо-краеведческая деятельность как средство социализации и воспитания подростков: автореф. дис. ... канд. наук. Ставрополь, 1998. $21 \mathrm{c.}$

18. Лагусев Ю.М. Теория и методика воспитательной деятельности в туризме: автореф. дис. ... дра пед. наук. М., 2002. 45 с.

19. Рябова Т.В. Педагогические условия организации детского туристического досуга // Культура и сервис: взаимодействие, инновации, подготовка кадров: сборник материалов I межрегион. науч.-практ. конф. 17 апреля 2009 г. / сост. В.Г. Велединский, Н.М. Мышьякова. СПб.: СПбГУСЭ, 2009. С. 78-79.

20. Сергеева С.А. Туризм как эффективное средство физического и нравственного воспитания школьников: автореф. дис. ... канд. пед. наук. М., 1996. $23 \mathrm{c}$.

21. Ариарский М.А. Социально-культурная деятельность как предмет научного осмысления. СПб.: Эго, 2008. $791 \mathrm{c.}$

\title{
THE CONTENT OF YOUNGER STUDENTS' SPIRITUAL AND MORAL EDUCATION BY MEANS OF EDUCATIONAL TOURISM
}

(C) 2019

\author{
Bakurova Tatyana Petrovna, candidate of pedagogical sciences, \\ associate professor of Pedagogy and Psychology Department \\ Siberian State University of Physical Education and Sport (Omsk, Russian Federation)
}

Abstract. This paper presents a systematic approach to the spiritual and moral education of primary school children, which is proposed to implement through a model that includes target, meaningful, subjective and effective components. All components of the model are described. For its implementation, forms of educational tourism were chosen, taking into account the age characteristics of children. The author described how to use different forms of tourism. A tourist activity application algorithm for younger students' spiritual and moral education is developed on the basis of a concentricity principle and assumes participation of students' parents. The presented model of spiritual and moral education is based on local history material and includes active and interactive forms and methods of work, which allows to develop knowledge as well as experience of moral behavior. The paper describes the modules of the world exploration consistently from exploring the city, the region and the country on the principle of «expanding and deepening spiral». The description of each form of educational tourism on the material of Omsk and Omsk Region is given. The author offers options for involving parents, options for creative assignments and final sessions for children. The model is ready for use and can serve as a basis for further research.

Keywords: spiritual and moral education; system approach; model of spiritual and moral education; younger students; educational tourism; forms of social and cultural activities; principle of concentricity; museum lesson; virtual tour; interactive tour; expedition; virtual journey; walk. 